\title{
Faktor-Faktor yang Mempengaruhi Produksi Gula Kelapa Skala Rumah Tangga
}

\author{
Factors Affecting Household-Scale Coconut Sugar Production
}

\author{
Amila Layaliya Faza ${ }^{1}$, Sri Wahyuningsih ${ }^{2}$, Shofia Nur Awami ${ }^{3}$, Lutfi Aris Sasongko ${ }^{4}$ \\ ${ }^{1,2,3,4}$ Program Studi Agribisnis Fakultas Pertanian, Universitas Wahid Hasyim Semarang
}

\section{ARTICLE INFO}

Article history:

DOI:

$\underline{10.30595 / \text { pspfs.v2i.201 }}$

Submitted:

July 29,2021

Accepted:

Sept 10, 2021

Published:

Nov 10, 2021

\section{Keywords:}

Coconut, Efficiency, Constraints, Productio, Sugar

\begin{abstract}
Many coconut plants grow and develop in Tunjungmuli Village which are cultivated by the surrounding community for the manufacture of palm sugar on a household scale. This study aims to determine the existence of constraints, factors that affect the production of palm sugar, and the level of economic efficiency of using palm sugar production factors. The method used is data stabilization, multiple linear regression analysis and marginal product value analysis, data collection is done by interview. Sampling was carried out using the simple random sampling method, which consisted of 36 craftsmen. The results showed that palm sugar production in Tunjungmuli Village, Karangmoncol District, Purbalingga Regency in February-March 2021 decreased due to extreme weather, erratic rains. The use of palm sugar production factors simultaneously has a significant effect on sugar production, the number of workers $(0.006)$, the number of juice $(0.000)$ and the number of plants tapped (0.000). Meanwhile, firewood $(0.018)$ and business experience $(0.815)$ did not have a significant effect on palm sugar production. The efficiency of the use of production factors, the amount of juice and the number of plants tapped has not been efficient because $>1$. While the number of workers, business experience and firewood $<1$ is not efficient, it needs to be reduced in use.
\end{abstract}

This work is licensed under a Creative Commons Attribution 4.0 International License.

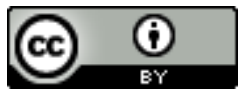

Corresponding Author:

Amila Layaliya Faza

Program Studi Agribisnis Fakultas Pertanian, Universitas Wahid Hasyim Semarang

Email: amilalayaliyafaza02@gmail.com

\section{PENDAhuluan}

Kabupaten Purbalingga merupakan salah satu daerah sentra tanaman kelapa dan penghasil gula kelapa yang sangat potensial di Jawa Tengah. Di Samping jumlah bahan baku gula kelapa yang melimpah dan murah, teknologi yang digunakan untuk membuat gula kelapa juga tidak membutuhkan biaya yang tinggi dan teknologi yang digunakan sederhana. Kelapa deres menjadi yang utama dimanfaatkan oleh masyarakat untuk diolah menjadi produk. Data statistik perkebunan Dinas Pertanian Purbalingga luas wilayah tanaman kelapa deres $5.459,27$ ha dengan jumlah petani 20.419 , produksi $41.969 .688,06 \mathrm{Kg}$ dan produktivitas $7.883,736 \mathrm{Kg} / \mathrm{Ha}$ (BPS, 2019).

Gula kelapa merupakan hasil olahan dari nira kelapa (Cocos nucifera L.). Nira didapat dengan cara penyadapan atau penderesan. Satu buah mayang dapat disadap selama 10-35 hari, namun produksi optimal selama 15 hari. Hasil nira sekitar 0,5-1 liter nira permayang (Pamuji, 2012). Setiap pohon rata-rata dapat menghasilkan 1,75 liter nira per hari. Jumlah nira yang hasilkan ini sangat dipengaruhi oleh keadaan iklim dan umur tanaman. Pada musim hujan, nira yang dihasilkan pada umumnya lebih banyak jika dibandingkan dengan 
musim kemarau. Demikian pula, nira yang dihasilkan oleh pohon kelapa muda lebih banyak dari pada nira yang dihasilkan oleh tanaman pohon yang sudah tua (Pracaya, 2016).

Desa Tunjungmuli Kecamatan Karangmoncol merupakan salah satu Kecamatan yang ada di Kabupaten Purbalingga yang sebagian besar wilayahnya memproduksi gula kelapa. Karakteristik usaha pengolahan gula kelapa di desa ini seperti halnya pengrajin gula di Desa Medono Kecamatan Kaliwiro Kabupaten Wonosobo. Mugiono (2014) menyampaikan bahwa proses produksi gula kelapa di Desa Medono masih menggunakan alat tradisional dan cara konvensional. Rata-rata pendapatan yang diterima pengrajin dalam satu bulan periode produksi sebesar Rp. 803.763, dan sekitar Rp.754.599 bagi pengrajin yang menyadap sendiri. Berdasarkan hal tersebut, maka penelitian ini bertujuan untuk: 1) apakah yang menjadi kendala pengrajin dalam memproduksi gula kelapa; 2) faktor-faktor apa saja yang mempengaruhi produksi; 3) bagaimana tingkat efisiensi penggunaan input produksi gula kelapa.

\section{METODE PENELITIAN}

Metode yang digunakan dalam penelitian ini adalah metode deskriptif. Metode pengambilan sempel responden dilakukan dengan simpel random sampling atau dipilih secara acak. Data yang digunakan meliputi data primer dan sekunder. Populasi secara keseluruhan pengrajin di Desa Tunjungmuli berjumlah 178 pengrajin, maka diambil sempel 15\% dari keseluruhan jumlah populasi yaitu 36 pengrajin. Jika jumlah subyek lebih dari 100 maka dapat diambil antara 10\%-15\% atau 20\%-25\% atau lebih dari jumlah populasi (Arikunto, 2010). Analisis data yang digunakan yaitu tabulasi data dan regresi linier berganda.

Metode analisis data yang digunakan dalam penelitian ini adalah persamaan regresi linear berganda, menurut Soekartawi (2002) sebagai berikut:

$\operatorname{Ln} Y=b_{0}+b_{1} \operatorname{Ln} x_{1}+b_{2} \operatorname{Ln} x_{2}+b_{3} \operatorname{Ln} x_{3}+b_{4} \operatorname{Ln} x_{4}+b_{5} \operatorname{Ln} x_{5}+e$

Keterangan:

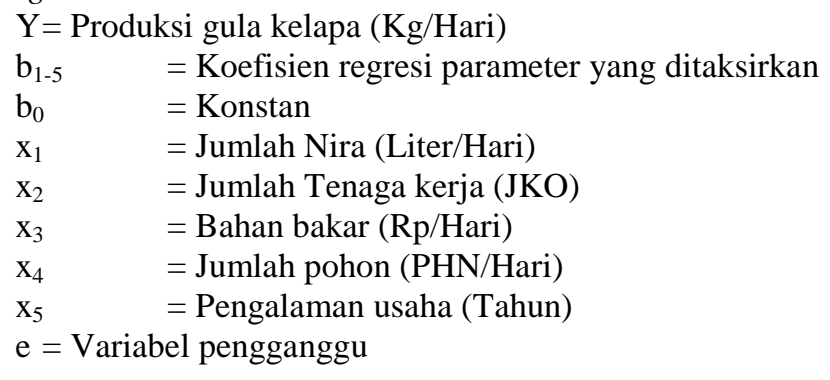

Selanjutnya juga menggunakan analisis ekonomi.

$\mathrm{NPM}_{\mathrm{X}}=\mathrm{P}_{\mathrm{X}} ;$ atau $\frac{\mathrm{NPM}_{\mathrm{X}}}{\mathrm{P}_{\mathrm{X}}}=1$
$\frac{\mathrm{NPM}_{\mathrm{X} 1}}{\mathrm{P}_{\mathrm{X} 1}}=\frac{\mathrm{NPM}_{\mathrm{X} 2}}{\mathrm{P}_{\mathrm{X} 2}}=\frac{\mathrm{NPM}_{\mathrm{X} 3}}{\mathrm{P}_{\mathrm{X} 3}}=\frac{\mathrm{NPM}_{\mathrm{X} 4}}{\mathrm{P}_{\mathrm{X} 4}}=\frac{\mathrm{NPM}_{\mathrm{X} 5}}{\mathrm{P}_{\mathrm{X} 5}}$

Keterangan:

$\mathrm{NPM}_{\mathrm{Xi}}=$ nilai produk margin untuk faktor produksi $\mathrm{X}_{\mathrm{i}}$

$\mathrm{P}_{\mathrm{X}} \quad=$ harga faktor produksi $\mathrm{X}_{\mathrm{i}}$

Dengan ketentuan :

$\frac{\mathrm{NPM}_{\mathrm{Xi}}}{\mathrm{P}_{\mathrm{Xi}}}=1, \quad$ berarti penggunaan faktor produksi xi mencapai efisiensi ekonomi
$\frac{\mathrm{NPM}_{\mathrm{Xi}}}{\mathrm{P}_{\mathrm{Xi}}} \neq 1, \quad$ berarti penggunaan faktor produksi xi tidak mencapai efisiensi ekonomi

\section{HASIL DAN PEMBAHASAN}

Berdasarkana Tabel 1. Karakteristik responden produksi gula kelapa dapat diketehui bahwa umur pengrajin gula di Desa Tunjungmuli mempunyai rata-rata umur 45 tahun. Pada umur tersebut pengrajin di Desa Tunjungmuli bisa dikatakan produktif dengan produktivitas masih cukup karena tenaga dan kemampuan yang dimiliki pengrajin masih maksimal untuk digunakan pada saat produksi. Pengalaman usaha pengrajin rata-rata lama menekuni pekerjaan 19 tahun. Pengrajin memiliki jumlah anggota keluarga rata-rata 4 jiwa. Sementara 
tingkat pendidikan pengrajin gula di Desa Tunjungmuli mayoritas tamat SD. Hal ini menunjukan bahwa tingkat pendidikan pengrajin di Desa Tunjungmuli masih rendah.

Tabel 1. Identitas Pengrajin Gula Kelapa Berdasarkan Kelompok Umur, Lama Menekuni Pekerjaan, Jumlah Anggota Keluarga dan Tingkat Pendidikan

\begin{tabular}{llccc}
\hline No. & Karakteristik & Keterangan & $\begin{array}{c}\text { Jumlah } \\
\text { (Orang) }\end{array}$ & $\begin{array}{c}\text { Persentase } \\
(\mathbf{\%})\end{array}$ \\
\hline 1. & Umur & $25-34$ & 4 & 11 \\
& & $35-44$ & 15 & 42 \\
& & $45-54$ & 11 & 30 \\
& & $55-64$ & 6 & 17 \\
\hline $2 . \quad$ Lama menekuni pekerjaan & $5-14$ & 13 & 36 \\
& & $15-24$ & 14 & 39 \\
& & $25-34$ & 8 & 3 \\
\hline 3. & Jumlah anggota keluarga & $35-44$ & 1 & 39 \\
& & $1-3$ & 14 & 56 \\
& & $4-6$ & 20 & 5 \\
\hline 4. & Tingkat pendidikan & $7-9$ & 2 & 64 \\
& & SD & 23 & 30 \\
\hline & Jumlah & SMP & 11 & $\mathbf{1 0 0}$ \\
\hline
\end{tabular}

Sumber : Analisis Data Primer, 2021

\section{Kendala Bahan Baku, Proses Produksi, dan Pemasaran}

Tabel 2. Kendala Bahan Baku, Proses Produksi dan Pemasaran Gula Kelapa Desa Tunjungmuli

\begin{tabular}{lllcc}
\hline No. & \multicolumn{1}{c}{ Kendala } & \multicolumn{1}{c}{ Keterangan } & Jumlah & Persentase \\
\hline 1. & Bahan Baku & Nira kotor (mengandung sekul) & 10 & 27 \\
\hline 2. & Proses Produksi & Keterampilan dan inovasi & 15 & 41 \\
& & Keterbatasan waktu & 19 & 53 \\
\hline \multirow{2}{*}{3.} & \multirow{2}{*}{ Pemasaran } & Lokasi gudang gula jauh & 15 & 42 \\
& & Tidak memiliki kendaraan & 8 & 22 \\
& Akses jalan kurang baik & 7 & 19 \\
\hline Jumlah & & $\mathbf{3 6}$ & $\mathbf{1 0 0}$ \\
\hline
\end{tabular}

Sumber: Analisis Data Primer, 2021.

Produksi gula kelapa pada penelitian bulan Februari-Maret 2021 di Desa Tunjungmuli mengalami penurunan akibat cuaca yang kurang baik, hujan tidak menentu dan setiap hari turun yang dapat mempengaruhi hasil dari nira. Kendala pada bahan baku yang dihadapi pengrajin berupa nira kotor dan basi, yang mengandung sekul. Sekul adalah istilah untuk nira yang banyak mengandung busa. Nira yang mengandung sekul biasanya terjadi karena suhu buruk.

Kendala dalam proses produksi gula lebih menuju pada proses pemasakan nira yang masih menggunakan alat sederhana dan tradisional. Dalam proses pemasakannya membutuhkan waktu yang lama kurang lebih $4-7$ jam tergantung pada jumlah nira yang diperoleh dan harus menjaga kestabilan nyala api, agar gula yang dihasilkan lebih baik. Upaya yang sekarang dilakukan responden pada proses produksi gula, lebih memaksimalkan kualitas produk dengan cara mengurangi penggunaan bahan tambahan dan menstabilkan nyala api agar kualitas baik.

Kendala pada pemasaran gula kelapa di Desa Tunjungmuli hasil produk belum terdaftar secara resmi sehingga pemasaran tidak dilakukan lebih luas untuk dapat dipasarkan di pasar modern atau super market, karena biasanya mensyaratkan adanya produk yang terdaftar secara resmi. Kendala yang lain lokasi penjualan jauh dari tempat tinggal yang mengharuskan membutuhkan trasportasi dan akses jalannya rusak. Upaya yang dilakukan pengrajin dalam mengatasi kendala pemasaran memilih untuk menjual gula ke warung terdekat atau menyuruh tukang ojek untuk mengantarkan.

\section{Analisis Faktor-Faktor Yang Mempengaruhi Produksi Gula Kelapa}

Hasil analisis Tabel 3. Menunjukan bahwa faktor yang mempengaruhi produksi gula kelapa dapat diformasikan dalam model sebagai berikut:

$\mathrm{LnY}=-10,586+5,789 \operatorname{LnX}_{1}+0,020 \operatorname{LnX}_{2}+0,152 \operatorname{LnX}{ }_{3}+0,127 \operatorname{LnX}_{4}-0,089 \operatorname{LnX} X_{5}+\mathrm{e}$ 
Berdasarkan hasil olah data dengan SPSS 16.00 menyatakan bahwa semua variabel terbebas dari uji asumsi klasik yang meliputi: uji normalitas, uji multikolineritas, uji heteroskedastisitas dan uji autokorelasi sehingga model regresi linier ini layak digunakan dalam penelitian. Adapun hasil analisis regresi faktor yang mempengaruhi produksi gula kelapa dapat disajikan pada Tabel 3.

Tabel 3. Hasil Analisis Regresi Faktor-Faktor Yang Mempengaruhi Produksi Gula Kelapa

\begin{tabular}{lccc}
\hline \multicolumn{1}{c}{ Variabel } & Koefisien Regresi & T-Hitung & Prob. Signifikan \\
\hline Konstanta & -10.586 & -1.902 & .067 \\
Jumlah Tenaga Kerja & 5.789 & 2.951 & $.006^{*}$ \\
Pengalaman Usaha & .020 & .236 & $.815^{\text {ns }}$ \\
Jumlah Tanaman Disadap & .152 & 5.303 & $.000^{*}$ \\
Jumlah Nira & .127 & 5.285 & $.000^{*}$ \\
Kayu Bakar &,- 089 & -2.505 & $.018^{* *}$ \\
\hline Koefisien Determinasi $\left(\mathrm{R}^{2}\right)$ & .923 & & \\
Adjusted R Square & .910 & & \\
F hitung & 71.679 & & \\
t tabel 5\% & 2,039 & & \\
Durbin Watson & 1,907 & & \\
\hline
\end{tabular}

Sumber: Analisis Data Primer, 2021

Keterangan :

* Signifikan pada tingkat kepercayaan $99 \%(\alpha 0,01)$

**Signifikan pada tingkat kepercayaan 95\% $(\alpha$ 0.05)

ns tidak signifikan

Nilai koefisien determinasi Adjusted R Squared sebesar 0,910. Hal ini menunjukan bahwa proporsi pengaruh variabel bebas (jumlah tenaga kerja, pengalaman usaha, jumlah pohon disadap, jumlah nira dan kayu bakar) terhadap variabel terikat (produksi gula kelapa) sebesar 91\% sedangkan sisanya 9\% dipengaruhi oleh variabel lain yang tidak terdapat pada model regresi linier dalam penelitian ini.

Uji $\mathrm{F}$ statistik dapat diketahui bahwa nilai $\mathrm{F}$ tabel dengan tingkat kesalahan $0,05(\alpha=5 \%)$ sebesar 2,534 dimana F hitung $(71,679) \geq \mathrm{F}$ tabel $(2,534)$ dan nilai signifikan $\leq 0,01$ maka dapat disimpulkan bahwa uji $\mathrm{F}$ Statistik diestimasi layak dan variabel bebas secara bersama-sama berpengaruh secara signifikan terhadap variabel terikat (produksi gula).

Uji t statistik dapat diketahui bahwa variabel bebas yang terdiri dari (jumlah tenaga kerja, jumlah tanaman disadap dan jumlah nira) secara nyata signifikan terhadap variabel terikat (produksi gula kelapa). Selaras dengan penelitian Yusnita (2018) yang menyatakan bahwa variabel jumlah tanaman disadap faktor produksi yang berpengaruh dan penelitian Wibisono (2012) menyatakan variabel nira berpengaruh signifikan terhadap produksi gula. Sedangkan pengalaman usaha dan kayu bakar tidak memberikan pengaruh yang signifikan terhadap produksi gula kelapa. Sesuai dengan penelitiannya Suyudi (2007) dan Puji (2018) yang menyatakan bahwa variabel pengalaman usaha dan kayu bakar tidak memberikan pengaruh yang signifikan terhadap variabel produksi gula kelapa.

\section{Efisiensi Penggunaan Faktor Produksi Gula Kelapa}

Tabel 4. Efisiensi Ekonomi Produksi Gula Kelapa Di Desa Tunjungmuli

\begin{tabular}{lccll}
\hline \multicolumn{1}{c}{ Variabel } & ET & EA & \multicolumn{1}{c}{ EE = ET x EA } & Keterangan \\
\hline Jumlah Tenaga Kerja & 0,205 & 1,568824593 & 0,321609 & Tidak efisien \\
Pengalaman Usaha & 0,004 & 123,7426901 & 0,494971 & Tidak efisien \\
Jumlah Tanaman Disadap & 0,565 & 5,938358376 & 3,355172 & Belum efisien \\
Jumlah Nira & 0,852 & 5,365571429 & 4,571467 & Belum efisien \\
Kayu Bakar & $-0,434$ & $-0,989594828$ & Tidak memenuhi syarat & Tidak efisien \\
\hline
\end{tabular}

Sumber: Analisis Data Primer, 2021

Berdasarkan tabel 4. Menyatakan bahwa efisiensi penggunaan faktor-faktor produksi pada usaha gula kelapa skala rumah tangga secara teknis penggunaan variabel input (jumlah tenaga kerja, pengalaman usaha, jumlah tanaman disadap, dan jumlah nira) tidak efisien perlu adanya peningkatan input produksi tersebut sampai efisiensi teknisnya mencapai 1 dan variabel kayu bakar tidak memenuhi syarat keharusan, sehingga perlu 
adanya pengurangan penggunaan. Sedangkan secara alokasi penggunaan variabel (jumlah tenaga kerja, pengalaman usaha, jumlah tanaman disadap, dan jumlah nira) tidak efisien dan variabel kayu bakar tidak memenuhi syarat kecukupan. Secara efisiensi ekonomi, penggunaan faktor produksi jumlah nira dan jumlah tanaman disadap belum efisien karena $>1$ perlu adanya penambahan penggunaan. Jumlah tenaga kerja dan pengalaman usaha $<1$ belum efisien perlu pengurangan penggunaan. Sedangkan kayu bakar tidak memenuhi syarat keharusan dan syarat kecukupan perlu adanya penataan ulang dalam penggunaan bahan bakar. Selaras dengan penelitianya Suyudi (2007) yang menyatakan bahwa faktor produksi tenaga kerja dan kayu bakar tidak efisien secara ekonomi perlu dilakukan pengurangan agar dapat mencapai tingkat efisien. Penggunaan kayu bakar yang tidak efisien, dapat diakibatkan karena penggunaan tungku yang masih tradisional, perlu penggunaan tungku modifikasi. Menurut Darmanto, dkk (2016) merancang tungku modifikasi. Hasil pengujian menunjukkan bahwa tungku modifikasi berhasil memperpendek waktu produksi menjadi 2-2,5 jam untuk memproses 10 liter nira menjadi gula. Jumlah kayu yang digunakan juga berkurang setengah dari jumlah kayu bakar yang digunakan pada tungku tradisional. Hal ini menunjukkan bahwa efisiensi tungku modifikasi sekitar dua kali dari tungku tradisional.

\section{KESIMPULAN}

1. Kendala bahan baku, beberapa pengrajin mengalami hasil nira yang diperoleh tidak baik terjadi kerusakan dan mengandung sekul. Kendala proses produksi, keterbatasan waktu karena alat yang digunakan masih tradisional, yang pemasakanya membutuhkan waktu yang lama dan harus menjaga kestabilan nyala api. Keterampilan dan inovasi pengrajin kurang berkembang sehingga mempengaruhi pendapatan. Kendala pemasaran, pengrajin belum mempunyai merek produk dan belum terdaftar secara resmi dalam UMKM sehingga pemasaran tidak dilakukan lebih luas untuk dapat dipasarkan di pasar modern. Kendala yang lain pada akses jalan yang rusak, tidak mempunyai kendaraan, lokasi gudang gula jauh.

2. Penggunaan input produksi (jumlah tenaga kerja, jumlah tanaman disadap, jumlah nira) secara simultan berpengaruh nyata terhadap produksi gula. Sementara variabel bebas berupa pengalaman usaha tidak berpengaruh nyata terhadap produksi gula kelapa.

3. Efisiensi penggunaan faktor produksi jumlah nira dan jumlah tanaman disadap belum efisien karena $>1$. Sedangkan jumlah tenaga kerja, pengalaman usaha dan kayu bakar $<1$ tidak efisien perlu pengurangan penggunaan.

\section{UCAPAN TERIMA KASIH}

Pada kesempatan ini penulis mengucapkan terimakasih yang sebesar-besarnya kepada semua pihak terutama pengajin gula kelapa Desa Tunjungmuli yang secara langsung maupun tidak langsung telah membantu dalam penyusunan penelitian ini.

\section{DAFTAR PUSTAKA}

Arikunto, Suharsimi. 2010. Prosedur Penelitian Suatu Pendekatan Praktek. Rineka Cipta: Jakarta.

Badan Pusat Statistik. 2019. Kabupaten Purbalingga Dalam Angka. BPS Kabupaten Purbalingga.

Darmanto., Priangkoso, T., Awami, SN. 2016. Modifikasi Tungku Untuk Meningkatkan Produktivitas Industri Rumah Tangga Gula Aren. Momentum, Vol. 12, No. 1, April, Hal. 60-63. Fakultas Teknik Universitas Wahid Hasyim. Semarang.

Mugiono., Marwanti, S., dan Awami, SN., 2014. Analisis Pendapatan Usaha Gula Merah Kelapa (Studi Kasus Di Desa Medono Kecamatan Kaliwiro Kabupaten Wonosobo. Jurnal Mediagro. Vol 10. No.2. Fakultas Pertanian Universitas Wahid Hasyim. Semarang.

Pamuji, Dwi A. 2012. Analisis Faktor-Faktor Yang Mempengaruhi Keuntungan Pengusaha Gula Kelapa (studi kasus di kecamatan kebasen kabupaten banyumas provinsi jawa tengah). Srikpsi. UNS: Surakarta.

Pracaya. P. C. Kahono. 2016. Budi Daya Kelapa. PT Sunda Kelapa Pustaka: Jakarta.

Puji. 2018. Analisis Faktor-Faktor Yang Mempengaruhi Produksi Gula Kelapa Di Desa Karya Tunas Jaya Kecamatan Tempuling Kabupaten Indragiri Hilir. Agribisnis Universitas Islam Indragiri. Jurnal Agribisnis UNISI. Vol 7 No 2. 2018, November, hal 62-75.

Soekartawi. 2002. Prinsip Ekonomi Pertanian. Rajawali Press: Jakarta.

Suyudi, Affan. Pujiharto dan Utami, Pujiati. 2007. Efesiensi Penggunan Faktor-Faktor Produksi Pada Usaha Pembuatan Gula Kelapa Di Desa Gumelum Wetan Kecamatan Susukan Kabupaten Banjarnegara. Jurnal Agritech. Vol 9. No 1. Hal 22-35. 
Wibisono, Gunawan. Istiyanti, Eni. dan Hasanah, Uswatun. 2012. Efesiensi Penggunaan Faktor-Faktor Produksi Gula Kelapa Di Desa Kunirejo Wetan Kecamatan Butuh Kabupaten Purwokerto. Jurnal Ilmu pertanian dan peternakan. vol 1. No 2. September 2012, hal 61-66.

Yusnita, S. D. 2018. Fungsi Produksi Dan Efisiensi Harga Penggunaan Faktor-Faktor Produksi Gula Kelapa. Skripsi. Universitas Siliwangi. 